Tropical Journal of Pharmaceutical Research September 2019; 18 (9): 1799-1804

ISSN: 1596-5996 (print); 1596-9827 (electronic)

(1) Pharmacotherapy Group, Faculty of Pharmacy, University of Benin, Benin City, 300001 Nigeria.

\title{
Effect of bazedoxifene on expressions of VEGF, VEGFR2, COX-2 and inflammatory factors in a rat endometriosis model
}

\author{
Rui Hou', Hao Xu' ${ }^{2}$, Hui $\mathrm{Li}^{1 \text { * }}$ \\ ${ }^{1}$ Nursing School, SIAS University of Zhengzhou, Zhengzhou, ${ }^{2}$ Department of Traditional Chinese Medicine, Affiliated Hangzhou \\ First Peoples Hospital, Zhejiang University School of Medicine, Hanzghou City 310006, China
}

*For correspondence: Email: ziy8xg@163.com

Sent for review: 6 March 2019

Revised accepted: 27 August 2019

\begin{abstract}
Purpose: To study the effect of bazedoxifene on the expressions of vascular endothelial growth factor (VEGF), soluble vascular endothelial growth factor receptor 2 (sVEGFR2), cyclooxygenase synthase 2 (COX-2) and inflammatory factors in a rat endometriosis (EMS) model.

Methods: Thirty rats (EMS) were divided into untreated control group, bazedoxifene group and celecoxib group (10 rats per group). Bazedoxifene and celecoxib were administered at doses of 3 and $25 \mathrm{mg} / \mathrm{kg}$, respectively. Negative control rats served as control, and were given $0.9 \%$ sodium chloride at a dose of $10 \mathrm{~mL} / \mathrm{kg}$. All treatments were given intragastrically for 21 days. Levels of VEGF, sVEGFR2 and COX-2 in uterine ectopic endometrium were assayed.

Results: The levels of VEGF and sVEGFR2 in the serum and peritoneal fluid of the untreated control group were significantly higher than the corresponding control values, while VEGF and sVEGFR2 levels in the serum and peritoneal fluid of the bazedoxifene group were significantly lower than those in the untreated control group ( $p<0.05)$. Bazedoxifene group had lower VEGFR2 and COX-2 levels than untreated control group $(p<0.05)$. Expression of COX-2 protein in the ectopic endometrium of celecoxib group was significantly lower than that in the untreated control group $(p<0.05)$.

Conclusion: Bazedoxifene alleviates angiogenesis and inflammatory factors in serum and peritoneal fluid of EMS rats, inhibits the expression of sVEGFR2 and COX-2 in ectopic endometrium, and also inhibits the growth of ectopic endometrium. This finding may help to discover additional new drugs.
\end{abstract}

Keywords: Bazedoxifene, Endometriosis, VEGF, VEGFR2, COX-2, Inflammatory factors

\begin{abstract}
This is an Open Access article that uses a fund-ing model which does not charge readers or their institutions for access and distributed under the terms of the Creative Commons Attribution License (http://creativecommons.org/licenses/by/4.0) and the Budapest Open Access Initiative (http://www.budapestopenaccessinitiative.org/read), which permit unrestricted use, distribution, and reproduction in any medium, provided the original work is properly credited.

Tropical Journal of Pharmaceutical Research is indexed by Science Citation Index (SciSearch), Scopus, International Pharmaceutical Abstract, Chemical Abstracts, Embase, Index Copernicus, EBSCO, African Index Medicus, JournalSeek, Journal Citation Reports/Science Edition, Directory of Open Access Journals (DOAJ), African Journal Online, Bioline International, Open-J-Gate and Pharmacy Abstracts
\end{abstract}

\section{INTRODUCTION}

Endometriosis (EMS) refers to the appearance, growth and formation of nodules and masses of endometrial tissue with growth function outside the endometrium [1]. The main clinical manifestations are chronic lower abdominal pain, dysmenorrhea and infertility. The associated histopathological changes are benign, but they have strong infiltration, invasion and metastasis [2]. In spite of several theories, the pathogenesis of EMS is still unknown. However, inflammation and vascular formation are considered as very important factors in the pathogenesis of EMS. 
Being an estrogen-dependent disease, the endometrium of postmenopausal ectopic lesions may gradually undergo atrophic absorption, and pregnancy and sex hormone drugs are used to inhibit ovarian function and prevent disease progression $[3,4]$. Clinically, EMS is treated with drugs that can reduce the production of endogenous estrogen, but long-term drug usage is needed before low estrogen symptoms appear. Therefore, there is clinical need for a drug that can inhibit the growth of ectopic lesions, improve pregnancy efficiency, and reduce EMS recurrence, with acceptable tolerance by patients [5].

Bazedoxifene is a third-generation estrogen receptor (ER) regulator with tissue selectivity which is antagonized by ER binding in the breast and uterus. Studies have shown that bazedoxifene significantly reduces ectopic lesions in the rat EMS model, and also reduces the expression of ER; these findings have raised its potential for development into a new drug for the treatment of EMS [6]. In the present study, an EMS rat model was established by autologous transplantation, and the mechanism of bazedoxifene action on EMS was investigated in two aspects: regulation of angiogenesis and inhibition of inflammatory factors.

\section{EXPERIMENTAL}

\section{Materials}

Thirty non-mating female SD rats, weighing 180 $200 \mathrm{~g}$ at 6 - 8 weeks old, were purchased from Shanghai Slack Laboratory Animals Co., Ltd. Bazedoxifene was product of Pfizer, USA; Celecoxib (> 99\%) was purchased from Shanghai Qiyi Biotechnology Co., Ltd. (Lot: 169590-42-5), while VEGF, VEGFR2, IL-1, IL-2, IL- 6 and TNF- $\alpha$ ELISA kits were products of TSZ. Rabbit anti-VEGFR2 antibody and rabbit antiCOX-2 antibody were obtained from CST; DAB chromogenic reagent was product of Vector Labs (Lot: SK4800); ECL Chemiluminescence detection kit was produced by Shanghai Tianneng Technology Co. Ltd (Lot: 180-501).

This research was approved by the Animal Ethical Committee of Department of Traditional Chinese Medicine, Affiliated Hangzhou First People's Hospital, Zhejiang University School of Medicine, Hanzghou City China (approval no. 20188379), and carried out according to "Principles of Laboratory Animal Care" (NIH publication no. 85-23, revised 1985) [7].

Paraffin slicer (RM2235) and DM750 optical microscope were purchased from Leica,
Germany; Cryogenic centrifuge (5430) was product of Eppendorf; Real-Time PCR instrument was produced by Applied Biosystems (ABI7500, AME), while Tanon4100 digital gel image processing system was product of Shanghai Tianneng Technology Co. Ltd, China.

\section{Establishment of rat EMS model}

The EMS rat model was established by autologous transplantation. Thirty-two (32) rats were anesthetized with $40 \%$ chloral hydrate $(0.4 \mathrm{~g} / 100 \mathrm{~g})$, following the steps of skin preparation, laparotomy, dye stripping, suture, and abdominal closure. Part of the endometrium was implanted between the abdominal muscles and the subcutaneous fascia, with the intima surface clinging to the abdominal muscles. After 3 weeks, secondary laparotomy indicated that the graft showed a cystic enlargement which was vesicular or nodular. The surface of the cyst wall had blood vessels and a small amount of connective tissue, indicating that the model was successfully established. Two rats did not have ectopic endometrial tissue on the inside of the abdominal wall.

\section{Rat grouping and drug administration}

Thirty model rats were randomly divided into untreated control group, bazedoxifene group and celecoxib group (10 rats per group). Bazedoxifene and celecoxib were administered at doses of $3 \mathrm{mg} / \mathrm{kg}$ and $25 \mathrm{mg} / \mathrm{kg}$, respectively. Un-operated rats served as control, and were given $0.9 \%$ sodium chloride at a dose of 10 $\mathrm{mL} / \mathrm{kg}$. All treatments were given intragastrically for 21 days. Twelve hours after the last administration, the rats were anesthetized, and intraperitoneal injection of PBS buffer was given. The peritoneal fluid was collected by gently pressing the abdomen. The abdominal cavity was opened, blood was collected from the abdominal aorta, and the rats were sacrificed. The ectopic endometrial lesions were obtained. The blood and peritoneal fluid were centrifuged at $3000 \mathrm{rpm}$ for $15 \mathrm{~min}$ at $4{ }^{\circ} \mathrm{C}$, and the supernatant portions were fixed in $4 \%$ paraformaldehyde, and partially stored in liquid nitrogen.

\section{Treatment indices}

The contents of VEGF, sVEGFR2 and inflammatory factors (IL-1, IL-2, IL-6 and TNF- $\alpha$ ) in serum and peritoneal fluid were determined using enzyme-linked immunosorbent assay (ELISA). All operations were performed in line with kit instructions. The expressions of VEGFR2 
and COX-2 were assayed using immunehistochemistry and Western blot.

\section{Statistical analysis}

Data were statistically analyzed using SPSS 17.0 software and are expressed as mean \pm standard deviation (mean \pm SD). Multiple comparison was performed with one-way analysis of variance (ANOVA), and LSD-t (Fisher's Least Significant Difference-t) test was used for comparison between two groups. Values of $p<0.05$ were considered statistically significant.

\section{RESULTS}

\section{Levels of VEGF and sVEGFR2}

The levels of VEGF and sVEGFR2 in serum and peritoneal fluid of untreated control group were significantly higher than those of the control group, and their levels in the bazedoxifene group were significantly lower than those in the untreated control group $(p<0.05)$. The content of VEGF in celecoxib group was significantly lower than that in untreated control group $(p<$ $0.05)$, but VEGF and sVEGFR2 levels in serum and peritoneal fluid were not significantly different from those in untreated control group ( $p$ $>0.05)$. These results are shown in Table 1.

\section{Expressions of inflammatory factors in peritoneal fluid of rats}

Table 2 shows that the contents of IL-1, IL-2, IL-6 and TNF- $\alpha$ in the peritoneal fluid of the untreated control group were significantly higher than those in the control group, while IL-1 IL-2, IL-6 and TNF- $\alpha$ levels in the peritoneal fluid of rats in the bazedoxifene group were significantly lower than those in the untreated control group $(p<0.05)$. The levels of IL-1, IL-2 and IL-6 in the peritoneal fluid of rats in the celecoxib group were significantly lower than those in untreated control group. However, the TNF- $\alpha$ contents of the celecoxib and untreated control groups were comparable $(p>0.05)$.

\section{Expressions of VEGFR2 and COX-2 in ectopic endometrium of rats}

Results from immunohistochemistry showed that VEGFR2 was expressed mainly in cytoplasm and membrane of vascular endothelial cells and glandular epithelial cells, and also slightly expressed in interstitial cells. In contrast, COX-2 was expressed mainly in glandular epithelial cells and interstitial cells in ectopic endometrium of rats. The positive expression levels of VEGFR2 and COX-2 in the ectopic endometrium of the bazedoxifene group were significantly decreased. In the celecoxib group, only the positive expression of COX-2 was significantly decreased (Figure 1 and Figure 2). Western blot analysis showed that the levels of VEGFR2 and COX-2 in the bazedoxifene group were significantly lower than those in the untreated control group $(p<0.05)$. COX-2 expression in the ectopic endometrium of the celecoxib group was significantly lower than in the untreated control group $(p<0.05)$. These results are shown in Figure 3.

Table 1: Levels of VEGF and sVEGFR2 in serum and peritoneal fluid of rats after treatment (mean \pm SD)

\begin{tabular}{|c|c|c|c|c|c|}
\hline \multirow[b]{2}{*}{ Group } & \multirow[b]{2}{*}{$\mathbf{n}$} & \multicolumn{2}{|c|}{ VEGF (pg/mL) } & \multicolumn{2}{|c|}{ sVEGFR2 (pg/mL) } \\
\hline & & Serum & $\begin{array}{l}\text { Peritoneal } \\
\text { fluid }\end{array}$ & Serum & Peritoneal fluid \\
\hline Control & 5 & $78.80 \pm 13.01$ & $83.05 \pm 5.74$ & $1286.27 \pm 285.47$ & $124.88 \pm 407.69$ \\
\hline $\begin{array}{l}\text { Untreated } \\
\text { control group }\end{array}$ & 10 & $173.67 \pm 28.56^{\star}$ & $\begin{array}{l}185.35 \pm \\
12.74^{*}\end{array}$ & $3273.68 \pm 594.25^{*}$ & $3714.25 \pm 152.98^{*}$ \\
\hline Bazedoxifene & 10 & $120.96 \pm 30.14^{\#}$ & $\begin{array}{c}116.32 \pm \\
18.01^{\#}\end{array}$ & $\begin{array}{l}2115.32 \pm \\
276.14^{\#}\end{array}$ & $2232.42 \pm 554.10^{\#}$ \\
\hline Celecoxib & 10 & $134.56 \pm 16.74^{* \#}$ & $\begin{array}{c}122.99 \pm \\
22.91^{\#}\end{array}$ & $2758.47 \pm 723.28$ & $2812.76 \pm 331.65$ \\
\hline
\end{tabular}

${ }^{\star} P<0.05$, compared with the control group; $\# p<0.05$, compared with untreated control group

Table 2: Levels of VEGF and sVEGFR2 in serum and peritoneal fluid of rats after treatment ( $\bar{x} \pm s$ )

\begin{tabular}{lccccc}
\hline Group & $\mathbf{n}$ & IL-1(ng/L) & IL-2(ng/L) & IL-6(pg/mL) & TNF- $\alpha(\mathbf{n g} / \mathbf{L})$ \\
\hline Control & 5 & $126.95 \pm 15.35$ & $993.97 \pm 101.25$ & $52.34 \pm 12.45$ & $221.54 \pm 24.26$ \\
Untreated & 10 & $226.54 \pm 16.82^{*}$ & $2135.54 \pm 99.32^{*}$ & $143.25 \pm 7.63^{*}$ & $511.64 \pm 19.46^{*}$ \\
control group & 10 & $161.25 \pm 30.35^{\#}$ & $1426.35 \pm 300.12^{\#}$ & $100.64 \pm 23.54^{\#}$ & $354.33 \pm 115.64^{\#}$ \\
Bazedoxifene & 10 & $141.42 \pm 36.05^{\#}$ & $1308.14 \pm 312.45^{\#}$ & $74.63 \pm 16.45^{\#}$ & $338.45 \pm 40.98^{* \#}$ \\
Celecoxib & 10 & with the control group; \#p<0.05, compared with untreated control group
\end{tabular}




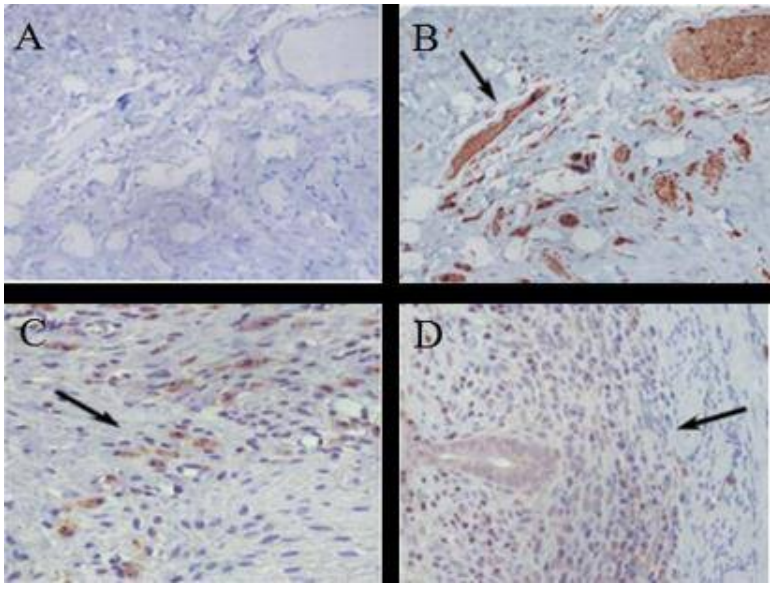

Figure 1: VEGFR2 expression in ectopic endometrium after treatment (DAB staining; $\times 400)$. A: Control, B: Model, C: Bazedoxifene, D: Celecoxib

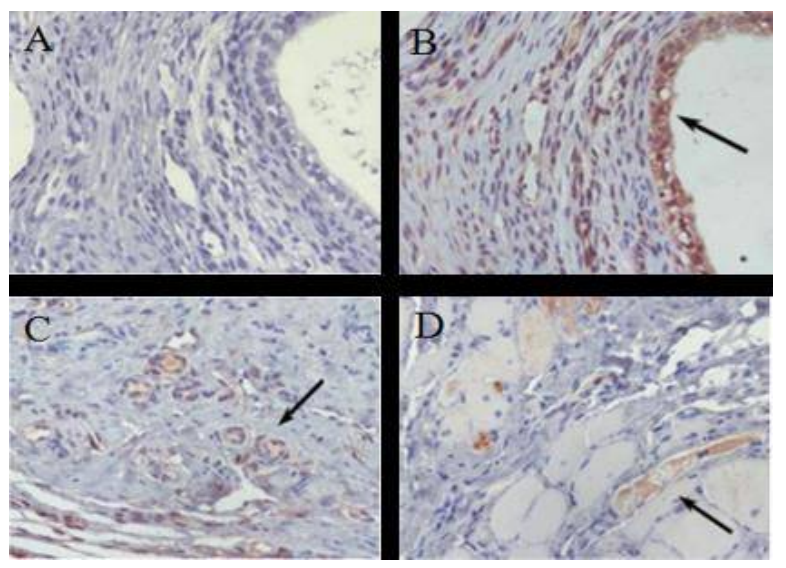

Figure 2: COX-2 expression in ectopic endometrium after treatment (DAB staining; $\times 400)$. A Control; B Model; C Bazedoxifene; D Celecoxib

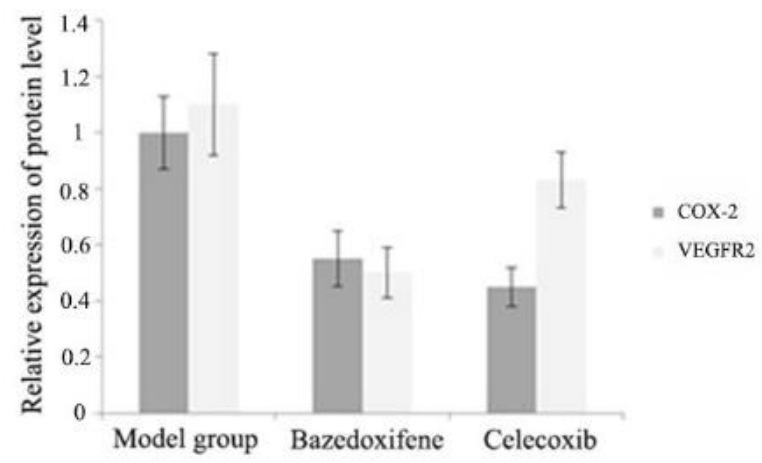

Figure 3: Expressions of VEGFR2 and COX-2 in ectopic endometrium of rats

\section{DISCUSSION}

Endometriosis (EMS) is a benign estrogendependent disease with strong malignant biological characteristics such as invasion, adhesion, recurrence, and malignant transformation [8]. The symptoms are caused by ectopic endometrial tissue implanted outside the uterus. Cyclooxygenase-2 (COX-2) is an important inducible enzyme in the inflammatory process. Studies have confirmed that COX-2 is involved in the formation of EMS, and is closely related to the occurrence and development of EMS [9].

Currently, clinical treatment of EMS is based mainly on surgery and drugs. Due to certain drawbacks of radical surgery, and poor receptivity, drug treatment is relatively more convenient. However, the clinically-used antiestrogen drugs cause adverse reactions such as high androgen symptoms, impairment of liver function, and dyslipidemia. Thus, patients' tolerance of these drugs is poor. Bazedoxifene is a representative drug of the third-generation SERM. It is used for postmenopausal osteoporosis, and it has no adverse effects on the endometrium. Moreover, it has a stronger antagonism against endometrial ER than raloxifene, and it is expected to become a new drug for the treatment of EMS $[10,11]$.

Vascular endothelial growth factor (VEGF) is a highly specific vascular endothelial cell mitogen which is currently recognized as the most important pro-angiogenic factor. It enhances the formation of new blood vessels by increasing vascular permeability and altering the gene expression of vascular endothelial cells [12]. On the other hand, VEGF also promotes mitosis of vascular endothelial cells by activating phospholipase C. It participates in extracellular proteolysis and degradation of basement membrane, and facilitates migration and proliferation of vascular endothelial cells. Studies have found that VEGF and its free receptor sVEGFR2 are upregulated in the peritoneal fluid of patients with EMS [13].

In the present study, the levels of VEGF and sVEGFR2 in the serum and peritoneal fluid of the untreated control group were significantly higher than those in the control group. The VEGF levels in the serum and peritoneal fluid of the two treatment groups were significantly decreased, and sVEGFR2 in the serum and peritoneal fluid of the celecoxib group decreased slowly. These results suggest that bazedoxifene acts on VEGF and its receptors, blocks VEGF from binding to its receptor, and affects angiogenesis. These findings are consistent with those reported by other scholars [14].

Cyclooxygenase-2 (COX-2) is a rate-limiting enzyme that catalyzes the conversion of phospholipid arachidonic acid to prostaglandins (PGs). It is upregulated by inflammatory mediators and cytokines, and it is involved 
mainly in the inflammatory process, transmission of pain signals and the occurrence of tumors. Studies have shown that COX-2 expression is significantly increased in the endometrium of patients with endometriosis [15]. This results in increased adhesion and invasiveness of endometrial cells. In recent years, studies have shown that immune regulation plays an important role in the occurrence and development of EMS. Impairment of the immune system is an intrinsic factor in the occurrence of EMS.

Some scholars have suggested that the number of macrophages in the peritoneal fluid of EMS model mice increase significantly, secreting a variety of inflammatory factors which promote the adhesion and invasion of the intima [16]. The results of the present study showed that the levels of IL-1, IL-2, IL- 6 and TNF- $\alpha$ in the peritoneal fluid of the untreated control group were significantly higher than those in the control group. The COX-2 expression was strong in the untreated control group, and in the bazedoxifene group, the contents of IL-1, IL-2, IL-6 and TNF- $\alpha$ in the peritoneal fluid of rats were significantly lower than those in the untreated control group. The reduction in COX-2 content in the ectopic endometrium of the two treatment groups was statistically significant, suggesting that bazedoxifene can significantly reduce the degree of inflammation in EMS rats. The underlying mechanism may be that bazedoxifene directly antagonizes the ER, but does not affect the expression of PR during the treatment.

\section{CONCLUSION}

Bazedoxifene significantly reduces the levels of angiogenesis and inflammatory factors in serum and peritoneal fluid of EMS rats; it inhibits the expression of VEGFR2 and COX-2 in ectopic endometrium, and affects the formation of ectopic intimal neovascularization as well as alters the inflammatory environment of the abdominal cavity, thereby inhibiting the growth of ectopic endometrium. Thus, bazedoxifene may be suitable for the clinical management of EMS.

\section{DECLARATIONS}

\section{Acknowledgement}

We acknowledge the support received from the management of the institutional hospital.

\section{Conflict of interest}

No conflict of interest is associated with this work.

\section{Contribution of authors}

We declare that this work was done by the author(s) named in this article and all liabilities pertaining to claims relating to the content of this article will be borne by the authors, all authors read and approved the manuscript for publication. Hao Xu conceived and designed the study, Hao Xu collected and analysed the data, Hao Xu wrote the manuscript.

\section{Open Access}

This is an Open Access article that uses a funding model which does not charge readers or their institutions for access and distributed under the terms of the Creative Commons Attribution License (http://creativecommons.org/licenses/by/ 4.0) and the Budapest Open Access Initiative (http://www.budapestopenaccessinitiative.org/rea d), which permit unrestricted use, distribution, and reproduction in any medium, provided the original work is properly credited.

\section{REFERENCES}

1. Vercellini $P$, Viganò $P$, Buggio L, Makieva S, Scarfone G, Cribiù FM, Parazzini F, Somigliana E. Perimenopausal management of ovarian endometriosis and related cancer risk: When is medical or surgical treatment indicated? Best Pract Res Clin Obstet Gynecol 2018; 51: $151-168$

2. Chapron C, Jacob S, Dubuisson JB, Vieira M, Liaras E, Fauconnier A. Laparoscopically assisted vaginal management of deep endometriosis infiltrating the rectovaginal septum. Acta Obstet Gynecol Scand 2015; 80(4): 349-354.

3. Borgfeldt C, Andolf E. Cancer risk after hospital discharge diagnosis of benign ovarian cysts and endometriosis. Acta Obstet Gynecol Scand 2015; 83(4): 395-400.

4. Su XH, Song DR, Zhang Y, Zhang W, Guo J, Wang YN, Zhao L. Study of Angiogenesis of Endometrial Stromal Cells in Endometriosis. J Int Obstet Gynecol 2015; 42(1): 49-53.

5. Du M, Ma G, Shi $Y$. Research progress on pharmacotherapy of calcific aortic valve disease. J Zhejiang Univ Med Sci 2016; 45(4): 432-438.

6. Li PC, Liu YL, Dang Q, Liu HL, Wang QM, Wang DL, Guo $P P, L v H J$, Tang FX, Huang $X H$. Effect of bardoxifene on the expression of ER, ER, AP-1, and VEGF in the ectopic endometrial tissues of endometriosis rats. Chin $J$ Obstet Gynecol 2016; 51(7): 541-543.

7. World Health Organization. Principles of laboratory animal care. WHO Chron 1985; 39: 51-56.

8. Anglesio MS, Papadopoulos N, Ayhan A, Nazeran TM, Noë M, Horlings HM, Lum A, Jones S, Senz J, Seckin T, et al. Cancer-Associated Mutations in Endometriosis

Trop J Pharm Res, September 2019; 18(9): 1803 
without Cancer. N Engl J Med 2017; 376(19): 1835 1848.

9. Yan WJ, Pi J, Yang Q. Expression and significance of MIF and COX-2 in endometriosis. Chin J Human Sex 2017; 26(12): 34-37.

10. Rudick CN, Woolley CS. Selective estrogen receptor modulators regulate phasic activation of hippocampal CA1 pyramidal cells by estrogen. Endocrinol 2016; 144(1): 179-187.

11. Li PC, Dang Q, Liu YL, Liu HL. Advances on selective ER regulator bazedoxifene. Chin J Obstet Gynecol 2016; 51(3): 225-227.

12. Leone RMU, Ferrero S. Methodological Concerns Regarding Levels of Vascular Endothelial Growth Factor (VEGF)in Serum of Women with Endometriosis. International J Fertil Steril 2015; 8(4): 485.

13. Ma Y, Li Y, Liu KR, Wang DB. Specific expression and significance of endocrine gland-derived vascular endothelial growth factor gene in ectopic and eutopic endometrium of patients with endometriosis. Chin J Pract Gynecol Obstet 2015; (4): 332-335.

14. Harada T, Ohta I, Endo $Y$, Sunada H, Noma H, Taniguchi F. SR-16234, a Novel Selective Estrogen Receptor Modulator for Pain Symptoms with Endometriosis: An Open-label Clinical Trial. Yonago Acta Med 2018; 60(4): 227.

15. He J, Xu Y, Yi MH, Gu CC, Hu GH. Effects of Qingre Huayu Formula on the Expression of VEGF, COX-2, $N F-K B$ in Endometriosis Rats. J Shanghai Univ Tradit Chin Med 2017; (2): 74-79.

16. Zhuang MF, Zhang TT, Sun ZG, Cao $Y$, Yu L, Shi $Y$, Yuan XF. Effect of Qingre Huayu Method on Angiogenesis and Expression of Inflammatory Related Factors in Rats with Endometriosis. Chin J Tradit Chin Med 2016; (5):1595-1599.

17. Lyu H, Liu Y, Dang $Q$, Chen $H$, Chen R. Effect of bazedoxifene on endometriosis in a rat model. Chin $J$ Obstet Gynecol 2015; 50(4): 291-295. 